DOI: $10.5277 /$ epe 160406

\title{
ADSORPTION OF COPPER, COBALT, AND MANGANESE IONS FROM AQUEOUS SOLUTIONS USING OXIDIZED MULTI-WALLED CARBON NANOTUBES
}

\begin{abstract}
Adsorption of $\mathrm{Cu}^{2+}, \mathrm{Co}^{2+}$, and $\mathrm{Mn}^{2+}$ metal ions on oxidized multi-walled carbon nanotubes (O-MWCNTs) was investigated as a function of contact time, $\mathrm{pH}$, sorbent dosage, and initial metal ion concentration. Multi-walled carbon nanotubes (MWCNTs) were oxidized using $\mathrm{HNO}_{3}$. All the adsorption experiments were conducted by the batch method. Determination of metal ions was performed by the flame atomic absorption spectrometry. The results showed that the amount of metal ions adsorbed strongly depended on $\mathrm{pH}$. The affinity order of the three adsorbed metal ions by O-MWCNTs was $\mathrm{Cu}^{2+}>\mathrm{Co}^{2+}>\mathrm{Mn}^{2+}$.
\end{abstract}

\section{INTRODUCTION}

Environmental pollution is one of the most important problems of today's life [1]. Industrial processes belong to main sources of heavy metals in the environment. In the developing countries, heavy metals are discharged straightly into environment and since these pollutants are non-biodegradable, they remain in the environment [2].

Accumulation of heavy metals in various organs including brain, kidneys, and liver can cause serious illness.Thus, removal of these materials from wastewater is the target of many studies in recent years. MWCNTs show excellent adsorption behavior, because of high surface to volume ratio, light weight, strength, large external surface area, and internal sites in their structures. However, application of these nanoparticles is limited due to their accumulation and stabilized bundles, which result from the van der Waals bonds among the graphene sheets in their structures. This problem can be overcome by surface modification of MWCNTs with various organic molecules [3]. Modification of

${ }^{1}$ Department of Chemistry, North Tehran Branch, Islamic Azad University, Tehran, Iran, e-mail: parvin.ehsaninamin@yahoo.com 
the MWCNTs surface have been reported in various studies for uptake of pollutants such as zinc [4], hexavalent chromium [5], nickel [6], lead [7], copper [8], and phenols [9].

MWCNTs modification by oxidation yields nanotubes with oxygen-containing functional groups such as carboxylic $(-\mathrm{COOH})$, carbonyl $(-\mathrm{C}=\mathrm{O})$, and hydroxyl $(\mathrm{O}-\mathrm{H})$ at both the sidewall and the end of nanoparticles [10]. Presence of these groups leads to better dispersion in water and improves the application of carbon nanotubes; especially as adsorbent of pollutants from the wastewater. In the case of oxidized treatment of MWCNTs, digestion of end caps of MWCNTs makes the inner channels accessible for adsorption of contaminants on the inside walls of the nanotubes.

In this work, surface modification of MWCNTs were conducted using $\mathrm{HNO}_{3}$ and characterized by scanning electron microscopy(SEM) and Fourier transform infrared (FTIR). The O-MWCNTs were applied for removal of $\mathrm{Cu}^{2+}, \mathrm{Co}^{2+}$ and $\mathrm{Mn}^{2+}$ in water samples.The effects of $\mathrm{pH}$, contact time, sorbent amount, and initial heavy metal concentration on the adsorption process were determined via the batch method. Determination of metal ions was performed by the atomic absorption spectrometry.

\section{EXPERIMENTAL}

Materials. MWCNTs with 20-30 nm outer diameter and $30 \mathrm{~nm}$ length were obtained from Cheap Tubes Inc. (USA). The purity of MWCNTs was more than $95 \%$. All reagents such as concentrated $\mathrm{HNO}_{3}(63 \%)$ and metal nitrates were purchased from Merck. Metal stock solutions $\left(1000 \mathrm{mg} \cdot \mathrm{dm}^{-3}\right)$ were prepared by dissolving salts in deionized water and then diluted to the required concentrations for standard solutions $\left(2-80 \mathrm{mg} \cdot \mathrm{dm}^{-3}\right)$.

Analytical methods. Concentration of heavy metals was measured by the flame atomic absorption spectrometry (FAAS) using Varian Model spectra AA.200 equipped with a single element hollow cathode (HCL) lamps, deuterium background correction, and air-acetylene. The surface functional groups of MWCNTs were detected by the FTIR spectrometer (EQUINOX 55) from 4000-400 $\mathrm{cm}^{-1}$. Morphology of oxidized MWCNTs was observed by Tescan VEGA-II scanning electron microscope. $\mathrm{pH}$ was adjusted using a Metrohm digital $\mathrm{pH}$ meter.

Sorbent preparation. The sorbent was prepared by treatment of pristine MWCNTs using $3 \mathrm{~mol} \cdot \mathrm{dm}^{-3} \mathrm{HNO}_{3}$. At first, $2 \mathrm{~g}$ of pristine MWCNTs were suspended in $\mathrm{HNO}_{3}$ and then sonicated in a water bath for $30 \mathrm{~min}$. The mixture was stirred at $110{ }^{\circ} \mathrm{C}$ for $48 \mathrm{~h}$. After cooling to the room temperature, the suspension of O-MWCNTs was added to $150 \mathrm{~cm}^{3}$ of deionized water, and then filtered. Washing the filtrate with deionized water was repeated until the solution became neutral. The adsorbent obtained was over night mounted in the vacuum oven for complete drying. 
Batch method procedure. The adsorption experiments were performed by the batch method. 5-30 mg of O-MWCNTs were added to $10 \mathrm{~cm}^{3}$ of the solution of metal ions in a triangular flask. Adjustment of the initial $\mathrm{pH}$ to $3-11$ was performed using either $0.1-0.01 \mathrm{~mol} \cdot \mathrm{dm}^{-3} \mathrm{HNO}_{3}$ or $\mathrm{NaOH}$. The flasks were shaken on a shaker at $160 \mathrm{rpm}$ at the room temperature. The final mixture obtained was centrifuged at $1600 \mathrm{rpm}$ for $15 \mathrm{~min}$, filtered, and its $\mathrm{pH}$ was measured.

Concentrations of residual heavy metal ions in the solution were measured by FAAS. The percentage of metal ions removed $(R)$ by the adsorbent was calculated from [11]:

$$
R=\frac{C_{0}-C_{t}}{C_{0}} \times 100
$$

where $C_{0}$ and $C_{t}$ are the initial concentration and concentration at time $t$ of the metal ions.

\section{RESULTS AND DISCUSSION}

\subsection{CHARACTERIZATION OF O-MWCNTs}

SEM images of pristine and O-MWCNTs are displayed in Fig. 1. The pristine MWCNTs have external diameters in the range of 20-30 nm. Many dark impurities can be observed in pristine MWCNTs, which correspond to the amorphous carbon and catalyst residues. It seems that the oxidation process considerably removed the dark particle impurities.
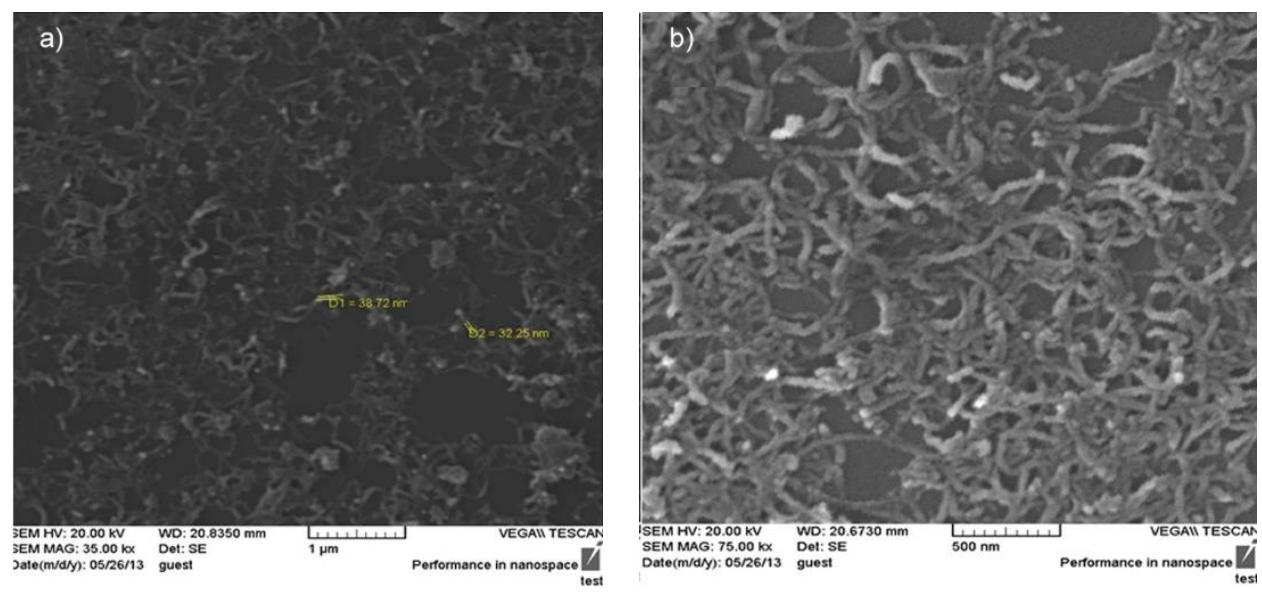

Fig. 1. SEM images of: a) MWCNTs, b) O-MWCNTs 
Some aggregations can be detected in these micrographs due to the van der Waals interactions among the carbon nanotubes with different shapes and directions. By comparing the size and shape of nanoparticles, one can find that the acidic modification has no significant effect on the shape and size of MWCNTs and only a smoother surface is obtained.

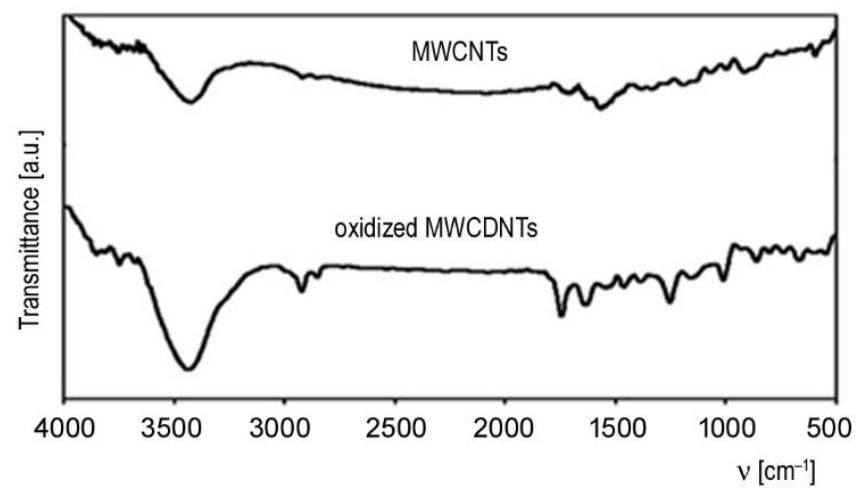

Fig. 2. FTIR spectra of MWCNT and O-MWCNT

FTIR spectra for the pristine MWCNTs and O-MWCNTs are presented in Fig. 2. The pristine MWCNTs exhibited the band at $3420 \mathrm{~cm}^{-1}$, which is related to O-H vibrations, and could be caused by water adsorption on MWCNTs. The FTIR spectra showed that after the nitric acid treatment, many functional groups appeared on the surface of nanoparticles. The presence of $\mathrm{O}-\mathrm{H}\left(3420 \mathrm{~cm}^{-1}\right), \mathrm{C}=\mathrm{O}\left(1730 \mathrm{~cm}^{-1}\right)$, and $\mathrm{C}-\mathrm{O}\left(1210 \mathrm{~cm}^{-1}\right)$ stretching vibrations in the FTIR spectra of O-MWCNTs confirms that oxidation of the MWCNTs was successfully done [12].

\subsection{EFFECT OF pH ON METAL REMOVAL EFFICIENCY}

The interaction between heavy metal ions and O-MWCNTs can be influenced by $\mathrm{pH}$. Heavy metal ions and charge of the adsorbent surface are controlled by this parameter $[13,14]$. It is well known that at $\mathrm{pH}$ values below the point of zero charge $\left(\mathrm{pH}_{\mathrm{pzc}}\right)$, the surface charge is mainly positive while at $\mathrm{pH}>\mathrm{pH}_{\mathrm{pzc}}$, the surface charge is predominantly negative. In acidic solutions, the low adsorption of metal ions on O-MWCNTs can be attributed to competition between $\mathrm{H}^{+}$and metal ions on the same sorption sites. It is clear that metal ion species in deionized water could be in forms of $\mathrm{M}^{2+}, \mathrm{M}(\mathrm{OH})^{+}$, $\mathrm{M}(\mathrm{OH})_{2}$, and $\mathrm{M}(\mathrm{OH})^{3-}[15]$. Figure 3 shows the dependence of percentage removal, of metal ions adsorbed onto the O-MWCNTs on $\mathrm{pH}$. As can be seen, removal of $\mathrm{Cu}^{2+}$, $\mathrm{Co}^{2+}$, and $\mathrm{Mn}^{2+}$ quickly increases at higher $\mathrm{pH}$. To avoid the interference of precipitation and adsorption, experiments were done at $\mathrm{pH}=5.7-6$. In this range, most metal ions in the solution are in the cation form and no precipitation occurs in the solution. Adsorption of heavy metal ions on O-MWCNTs can be explained by three mechanisms: Firstly, cation exchange reaction between $\mathrm{H}^{+}$of carboxylic groups and metal ions, secondly, 
formation of surface complex, and finally entrance of metal ions to the inner channel of MWCNTs. In order to clarify the reaction mechanism, the final $\mathrm{pH}$ of the solution was measured in each experiment. It was found that $\mathrm{pH}$ of the solutions decreased at the end of the experiments (equilibrium state). For example, the $\mathrm{pH}$ value for the solution of metal ions decreased by $0.5-0.7$. This decrease can be explained by ion exchange between $\mathrm{H}^{+}$ions of the carboxylic groups and metal cations in the solution. However, carboxyl and hydroxyl functional groups on the surface of O-MWCNTs can form complex with metal ions or hydroxyl metal cations, which is not negligible. Adsorption of metal ions on O-MWCNTs is a complicated process, which is the other mechanism probably participating in the removal process.

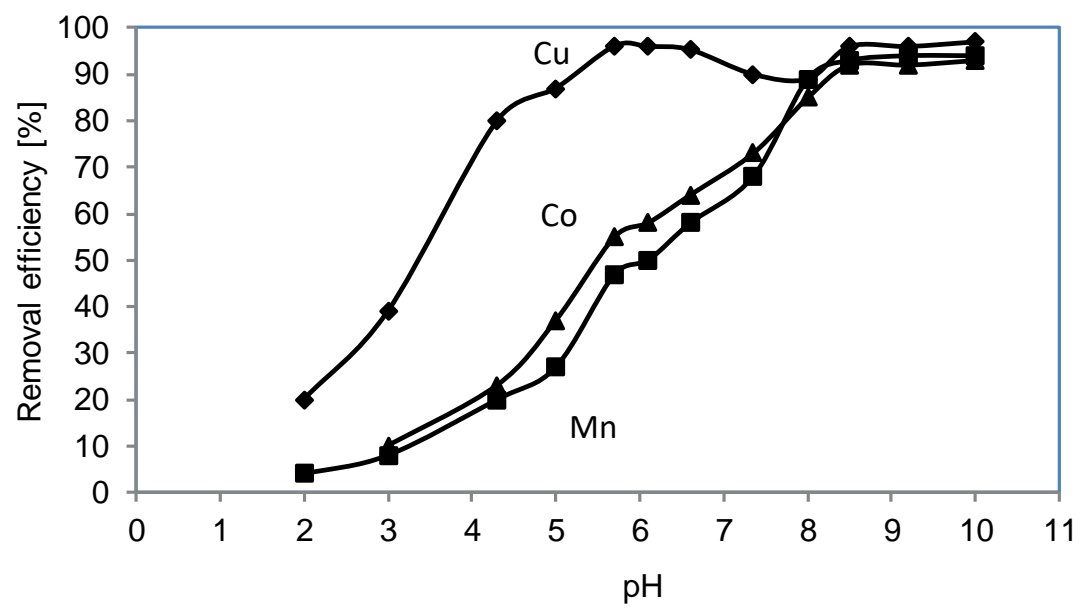

Fig. 3. Dependences of percentage removal of $\mathrm{Cu}^{2+}, \mathrm{Mn}^{2+}$, and $\mathrm{Co}^{2+}$ ions on $\mathrm{pH}$

\subsection{REGENERATION OF SORBENT}

Desorption of the metal ions loaded was carried out at $\mathrm{pH}<3$. For the desorption study of O-MWCNTs, adsorption experiments were conducted at initial metal ions concentration of $30 \mathrm{mg} \cdot \mathrm{dm}^{-3}$ (similar to the batch experiment). Then the sorbent was kept at $50{ }^{\circ} \mathrm{C}$ for $2 \mathrm{~h}$ and then added to deionized water at $\mathrm{pH}<3$ (using $\mathrm{HNO}_{3}$ ). Removal of metal ions from O-MWCNTs was determined using FAAS. After regeneration of the sorbent, O-MWCNTs were washed with deionized water and used in further tests. Adsorption/desorption cycles were repeated and the efficiency of heavy metal desorption amounted to $97 \pm 3 \%, 95.8 \pm 2 \%$, and $96.8 \pm 3 \%$ for $\mathrm{Cu}^{2+}, \mathrm{Mn}^{2+}$, and $\mathrm{Co}^{2+}$, respectively.

\subsection{CONTACT TIME STUDIES}

Contact time is a reflection of the adsorption rate, which determines the time required for perfect adsorption. Effect of contact time was monitored by the batch method 
in 15 min steps and the concentration of each heavy metal ion in the solution was measured by FAAS in each step. In Figure 4, percentage removal of heavy metal ions from the aqueous solution by O-MWCNTs is shown as a function of the contact time. As can be seen, after $60 \mathrm{~min}$ of contact, removal of heavy metals remained fixed; thus, for all the experiments contact time of $60 \mathrm{~min}$ was considered.

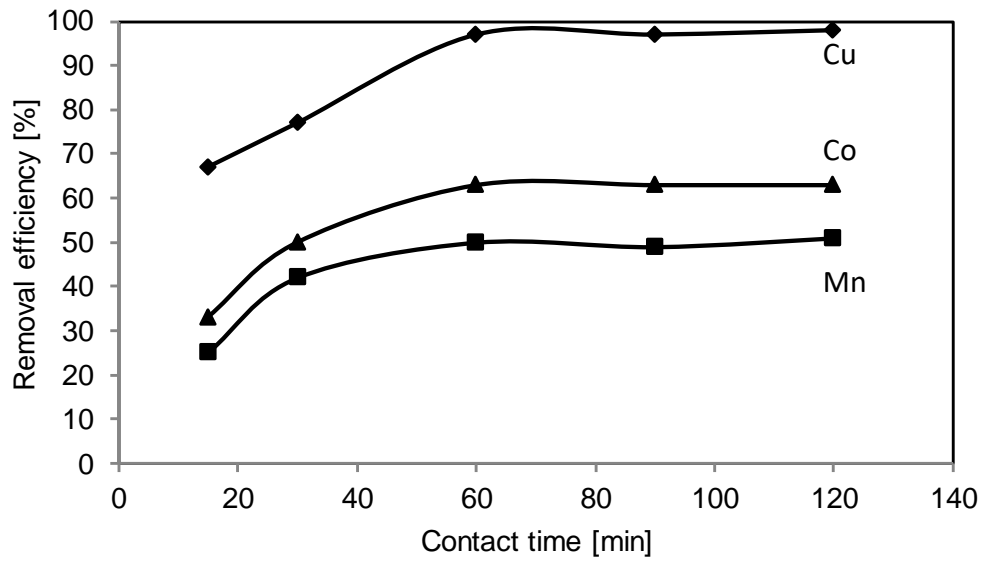

Fig. 4. Time dependences of percentage removal of $\mathrm{Cu}^{2+}, \mathrm{Mn}^{2+}$, and $\mathrm{Co}^{2+}$ ions

\subsection{EFFECT OF SORBENT AMOUNT ON METAL REMOVAL EFFICIENCY}

The influence of adsorbent amount on the efficiency of removal of heavy metals from the aqueous solution was investigated by increasing the sorbent amount in the range of 5-30 mg under optimal values for other variables. The efficiency of removal of heavy metal ions increased with the increase of adsorbent, as shown in Fig. 5.

Adsorption of heavy metal ions on O-MWCNTs reached the maximum value with sorbent dosage of $10 \mathrm{mg}$. This phenomenon can be explained by increase in the binding sites on higher amounts of the adsorbent. In other words, high adsorbent amount provided more adsorption sites for attachment of metal ions and this accessibility greatly improve the adsorption of metal ions.

\subsection{ADSORPTION CAPACITY}

The amount of sorbent required for analyte extraction from the solution was determined by sorption capacity. For this purpose, a suspension of $10 \mathrm{mg}$ of O-MWCNTs in $10 \mathrm{~cm}^{3}$ of heavy metal solution under the initial conditions $\left(2-60 \mathrm{mg} \cdot \mathrm{dm}^{-3}\right.$ and $\mathrm{pH}$ 5.7-6) was prepared. After $60 \mathrm{~min}$ of shaking, the liquid phase was separated from the solid phase and residual metal ion concentrations were measured by FAAS. The amount of adsorbed cations $\left(Q\right.$ in $\left.\mathrm{mg} \cdot \mathrm{g}^{-1}\right)$ was plotted in function of the initial concentration $\left(\mathrm{C}_{0}\right.$ in $\left.\mathrm{mg} \cdot \mathrm{dm}^{-3}\right)$ in Fig. 6. 


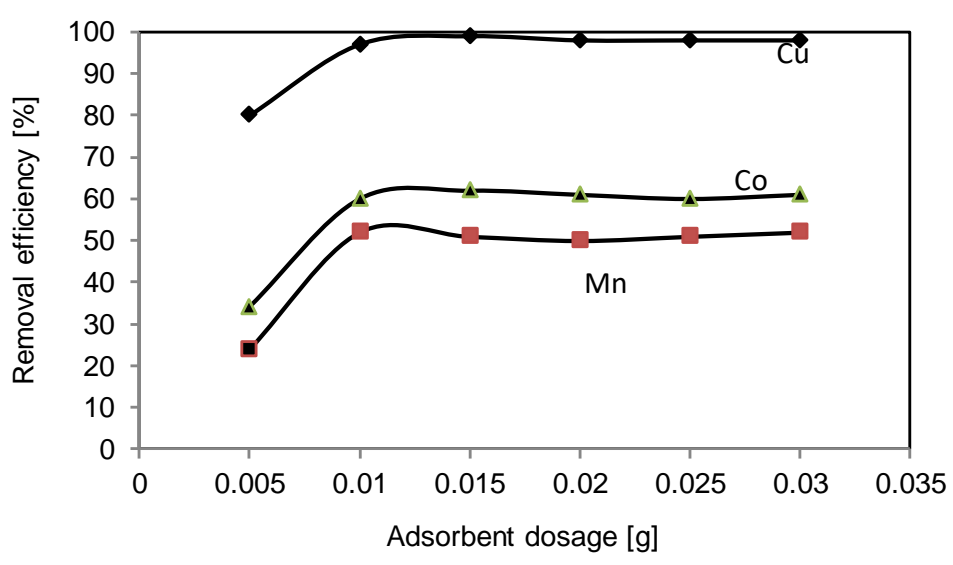

Fig. 5. Dependences of percentage removal of $\mathrm{Cu}^{2+}, \mathrm{Mn}^{2+}$, and $\mathrm{Co}^{2+}$ ions on sorbent dosage

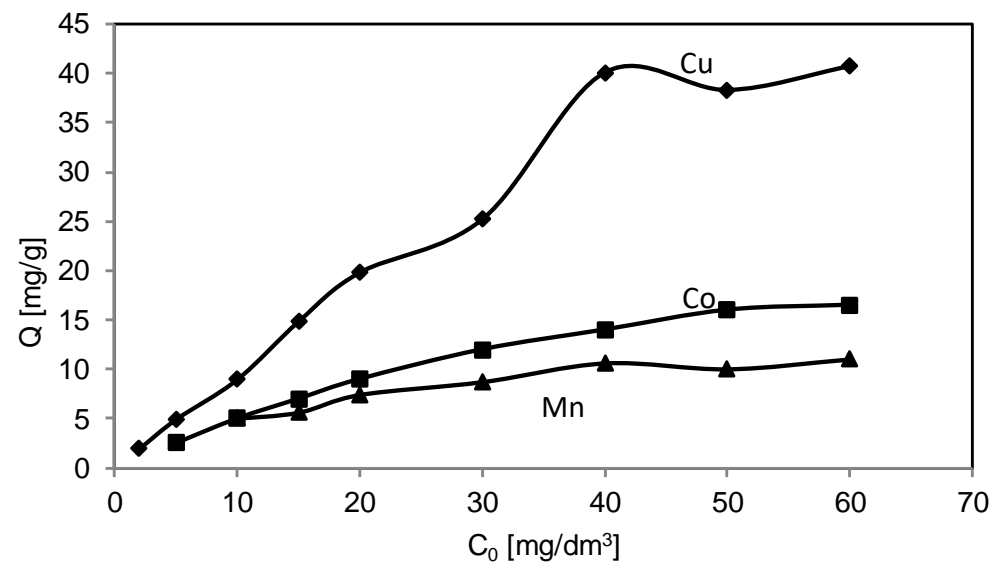

Fig. 6. Adsorption capacity $Q$ of $\mathrm{Cu}^{2+}, \mathrm{Mn}^{2+}$, and $\mathrm{Co}^{2+}$ ions on O-MWCNT

$Q$ was calculated according to the following equation [12]:

$$
Q=\frac{\left(C_{0}-C_{e}\right) V}{M}
$$

where $C_{e}$ is the equilibrium concentration of metal ions in $\mathrm{mg} \cdot \mathrm{dm}^{3}, M$ - the adsorbent weight in $\mathrm{g}$, and $V$ is the volume of metal ion solutions in $\mathrm{dm}^{3}$. As can be seen, $\mathrm{Cu}^{2+}$ ions show the highest adsorption in comparison to $\mathrm{Co}^{2+}$ and $\mathrm{Mn}^{2+}$. The main reason for this trend is higher electronegativity of $\mathrm{Cu}$. In other words, higher eletronegativity of a metal ion represents its higher attraction for electrons and attraction for negative charges plays a major role in the adsorption phenomenon. 


\subsection{ADSORPTION ISOTHERM}

The Langmuir and Freundlich models were used for modeling the adsorption isotherms [16]. According to the Langmuir equation (the most extensively used), adsorption is monolayer and all adsorbed molecules have equal energy. The Langmuir equation is:

$$
q_{e}=\frac{b q_{m} C_{e}}{1+b C_{e}}
$$

where $C_{e}$ and $q_{e}$ are metal ion concentrations in the liquid and solid phases, respectively, $q_{m}$ is the maximum amount of metal ion adsorbed, and $b$ is the Langmuir constant that indicates the affinity of binding sites on the adsorbent surface. In the linear form, the Langmuir isotherm equation is:

$$
\frac{C_{e}}{q_{e}}=\frac{C_{e}}{q_{m}}+\frac{1}{b q_{m}}
$$

$q_{m}$ and $b$ values may be calculated from the intercept and slope of $1 / q_{e}$ vs. $1 / C_{e}$.

The Freundlich model is usually adopted for adsorption from liquid phase on heterogeneous surfaces (like O-MWCNTs). The Freundlich model is:

$$
q_{e}=K_{f} C_{e}^{1 / n}
$$

where $K_{f}$ and $n$ are the Freundlich constants related to the capacity and power of adsorption, respectively.The linear form of the Freundlich isotherm is given as:

$$
\ln q_{e}=\ln K_{f}+\frac{1}{n} \ln C_{e}
$$

This model shows that the ratio of the adsorbed metal ion content onto the adsorbent to the concentration of metal ion in the solution varies in function of metal ion concentration. The adsorption isotherms of heavy metal ions on O-MWCNTs at $\mathrm{pH}$ in the range of 5.7-6 are shown in Fig. 7.

The experimental data for each heavy metal was fitted to the models considered. The parameters calculated for the models and the correlation coefficients are reported in Table 1. 


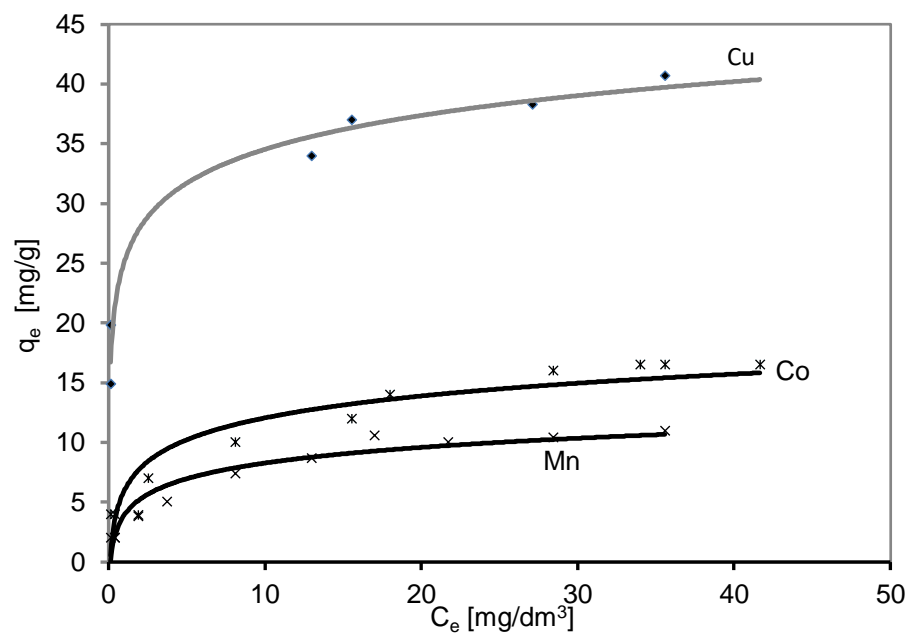

Fig. 7. Adsorption isotherm of $\mathrm{Cu}^{2+}, \mathrm{Mn}^{2+}$, and $\mathrm{Co}^{2+}$ ions on O-MWCNT

Table 1

Langmuir and Freundlich isotherm parameters for adsorption of metal ions onto O-MWCNTs

\begin{tabular}{|c|c|c|c|c|c|c|}
\hline \multicolumn{3}{|c|}{ Freundlich model } & \multicolumn{3}{c|}{ Langmuir model } \\
\hline Metal ion & $K_{f}$ & $n$ & $r^{2}$ & $b$ & $\begin{array}{c}q_{\max } \\
{[\mathrm{mg} / \mathrm{g}]}\end{array}$ & $r^{2}$ \\
\hline $\mathrm{Cu}^{2+}$ & 15 & 3.19 & 0.841 & 2.04 & 53 & 0.989 \\
\hline $\mathrm{Co}^{2+}$ & 4.9 & 1.66 & 0.986 & 0.047 & 26.3 & 0.998 \\
\hline $\mathrm{Mn}^{2+}$ & 2.29 & 2.45 & 0.985 & 0.080 & 13.33 & 0.955 \\
\hline
\end{tabular}

The correlation coefficients for the Langmuir model in the cases of $\mathrm{Cu}^{2+}, \mathrm{Co}^{2+}$ and $\mathrm{Mn}^{2+}$ are higher than those of the Freundlich model.This model better demonstrates the adsorption behavior of $\mathrm{Cu}^{2+}, \mathrm{Co}^{2+}$, and $\mathrm{Mn}^{2+}$ on O-MWCNTs and can be concluded that the adsorption is in the monolayer form. In addition, the values obtained for $n$ from the isotherm models were larger than unity, which indicates desirable adsorption on O-MWCNTs. The maximum adsorption capacities based on the Langmuir equation were 53, 26.3, and $13.33 \mathrm{mg} \cdot \mathrm{g}^{-1}$ for $\mathrm{Cu}^{2+}, \mathrm{Co}^{2+}$ and $\mathrm{Mn}^{2+}$, respectively, indicating good adsorption capacities for this sorbent.

\section{CONCLUSIONS}

O-MWCNTs were prepared with the ability to remove heavy metal ions $\left(\mathrm{Cu}^{2+}\right.$, $\left.\mathrm{Mn}^{2+}, \mathrm{Co}^{2+}\right)$ from wastewater by an efficient surface modification method. Oxidation of 
MWCNTs was conducted with nitric acid to produce oxygen-containing functional groups via covalently bound (such as $-\mathrm{COOH},-\mathrm{OH},-\mathrm{CO}$ ) on the surfaces of MWCNTs. Surface modification of MWCNTS $_{\mathrm{S}}$ with nitric acid enhances their adsorption capacity for heavy metal ions and generates a fine sorbent for removal of heavy metal ions in wastewater.The main reason for adsorption of heavy metal ions on the surface of the O-MWCNTs originates from ion exchange reaction mechanism. $\mathrm{pH}$ has the main role in adsorption process and the amount of heavy metal adsorbed onto the O-MWCNTs was increased as $\mathrm{pH}$ increased. The quantity of adsorbed $\mathrm{Cu}^{2+}, \mathrm{Co}^{2+}$, and $\mathrm{Mn}^{2+}$ on the O-MWCNTs was determined in the following order $\mathrm{Cu}^{2+}>\mathrm{Co}^{2+}>\mathrm{Mn}^{2+}$. This trend is consistent with higher electronegativity and first stability constant of ion hydroxide.

The Langmuir isotherm model agrees well with the equilibrium experimental data for each heavy metal ion. Regarding the Langmuir equation, the maximum adsorption capacity values for $\mathrm{Cu}^{2+}, \mathrm{Co}^{2+}$, and $\mathrm{Mn}^{2+}$ were $53,26.3$ and $13.33 \mathrm{mg} / \mathrm{g}$, respectively.

\section{REFERENCES}

[1] Weber R., Watson A., Persistent organic pollutants and landfills. A review of past experiences and future challenges, Waste Manage. Res., 2011, 29, 107.

[2] Coen N., Mothersill C., KAdHIM M., Wright E.G., Heavy metals of relevance to human health induce genomic instability, J. Pathol., 2001, 195, 293.

[3] BalasubramANiAn K., BuRghaRd M., Electrochemically functionalized carbon nanotubes for device applications, J. Mater. Chem., 2008, 18, 3071.

[4] StAFiej A., PyrZYNSKa K., Solid phase extraction of metal ions using carbon nanotubes, Microchem. J., 2008, 89, 29.

[5] Pill K., Cukrowska E.M., Coville N.J., Multi-walled carbon nanotubes as adsorbents for the removal of parts per billion levels of hexavalent chromium from aqueous solution, J. Hazard Mater., 2009, 166, 1067.

[6] Yang S., Li J., Shao D., Hu J., Wang X., Adsorption of Ni(II) on multi-walled carbon nanotubes. Effect of contact time, pH, foreign ions and PAA, J. Hazard Mater., 2009, 166, 109.

[7] Xu D., TAN X., CHEN C., WANG X., Removal of Pb(II) from aqueous solution by oxidized multiwalled carbon nanotubes, J. Hazard Mater., 2008, 154, 407.

[8] Li Y.H., Ding J., LuAN Z.K., Di Z.C., ZhuY.F., Xu C.L., Wu D.H., WeI B.Q., Competitive adsorption of $\mathrm{Pb}^{2+}, \mathrm{Cu}^{2+}$ and $\mathrm{Cd}^{2+}$ ions from aqueous solutions by multiwalled carbon nanotubes, Carbon, 2003, 41, 2787.

[9] LiU X., Ji Y., Zhang Y., Zhang H., LiU M., Oxidized multiwalled carbon nanotubes as a novel solid phase micro extraction fiber for determination of phenols in aqueous samples, J. Chromat. A., 2007, $1165,10$.

[10] Rosca I.D., Watari F., Uo M., AKaSAKa T., Oxidation of multiwalled carbon nanotubes by nitric acid, Carbon, 2005, 43, 3124.

[11] Lu C., CHIU H., Adsorption of zinc (II) from water with purified carbon nanotubes, Chem. Eng. Sci., 2006, 61, 1138.

[12] TeHRANi M.S., AzAR P.A., NAmin P.E., Removal of lead from wastewater using functionalized multiwalled carbon nanotubes with tris(2-aminoethyl)amine, J. Environ. Prot., 2013, 4, 529.

[13] PYRZYNSKA K., Carbon nanostructures for separation, preconcentration and speciation of metal ions, Trends Anal. Chem., 2010, 29, 718. 
[14] AfKhami A., SABer-Tehrani M., BAgheRi H., Flame atomic absorption spectrometric determination of trace amounts of $\mathrm{Pb}(\mathrm{II})$ and $\mathrm{Cr}(\mathrm{III})$ in biological, food and environmental samples after preconcentration by modified nano-alumina, Micro Acta, 2011, 172, 125.

[15] Weng C-H., Modeling Pb(II) adsorption onto sandy loam soil, J. Collid. Inter. Sci., 2004, 272, 262.

[16] Wu C.-H., Studies of the equilibrium and thermodynamics of the adsorption of $\mathrm{Cu}^{2+}$ onto as-produced and modified carbon nanotubes, J. Colloid. Inter. Sci., 2007, 311, 338. 